\title{
The Major Psychocutaneous Disorders in Iraqi Patients
}

\author{
Khalifa E. Sharquie ${ }^{1,2 *}$, Adil A. Noaimi1,2, Maha S. Younis ${ }^{3}$, Bashar S. Al-Sultani ${ }^{4}$ \\ ${ }^{1}$ Department of Dermatology, College of Medicine, University of Baghdad, Baghdad, Iraq \\ ${ }^{2}$ Iraqi and Arab Board for Dermatology and Venereology, Baghdad Teaching Hospital, Baghdad, Iraq \\ ${ }^{3}$ Department of Psychiatry, College of Medicine, University of Baghdad, Baghdad, Iraq \\ ${ }^{4}$ Department of Dermatology, Baghdad Teaching Hospital, Baghdad, Iraq \\ Email: "ksharquie@ymail.com, adilnoaimi@yahoo.com, maha.younis@gmail.com, \\ bashar-sami83@yahoo.com
}

Received 24 February 2015; accepted 18 March 2015; published 20 March 2015

Academic Editor: Bouzid Menaa, Fluorotronics, Inc., USA

Copyright (C) 2015 by authors and Scientific Research Publishing Inc.

This work is licensed under the Creative Commons Attribution International License (CC BY).

http://creativecommons.org/licenses/by/4.0/

(c) (i) Open Access

\section{Abstract}

Background: Many skin diseases can be evoked by psychological problems. Dermatological conditions could also lead to psychological disorders; hence psychodermatology is an emerging subspecialty that focuses on the interface of psychiatry and dermatology. Objective: To assess the frequency of the major disorders of so-called psychocutaneous disorders which are commonly seen among Iraqi population. Patients and Methods: This case descriptive study had been done in Department of Dermatology-Baghdad Teaching Hospital, Medical City, Baghdad, Iraq during the period from March 2011 to October 2013. All cases were collected and categorized according to the disease problem. Patients were interviewed to search for the main triggering and precipitating factors involved in pathogenesis of these disorders. The clinical picture was well described in order to reach a final diagnosis. Psychological interview and analysis were performed for all patients to reach the specific emotional and psychiatric disease by consultant psychiatrist. Results: A total of 100 patients with major psychocutaneous disorders were seen and evaluated. Nineteen were males and 81 were females with female to male ratio: 4.26:1. Their ages ranged from 7 - 73 (26.5 \pm 5.217) years. The frequency of these diseases was as follows: trichotillomania $53 \%$, dermatitis artifacta $37 \%$, delusion of parasitosis $6 \%$ and neurotic excoriation $4 \%$. Conclusions: The major psychocutaneous diseases in Iraqi population were: trichotillomania, dermatitis artifacta and these are problems of mainly young females while delusion of parasitosis and neurotic excoriations were diseases of middle age females.

${ }^{*}$ Corresponding author.

How to cite this paper: Sharquie, K.E., Noaimi, A.A., Younis, M.S. and Al-Sultani, B.S. (2015) The Major Psychocutaneous Disorders in Iraqi Patients. Journal of Cosmetics, Dermatological Sciences and Applications, 5, 53-61. 


\section{Keywords}

\section{Trichotillomania, Dermatitis Artifacta, Delusion of Parasitosis, Neurotic Excoriation,} Psychocutaneous Disorders, Iraqi Patients

\section{Introduction}

Psychodermatology comprises any aspect of dermatology with psychological or psychiatric elements [1]. The association between skin and the nervous system is related to their common embryonic origin, the ectoderm. The nervous system and the skin begin to form and develop side by side on the top layer or ectoderm of the fetus and remain intimately interconnected and interactive throughout life [2]. The neural receptors in the skin may be viewed as the largest sense organ of the body and are key to skin protection and health [3].

The scope of psychodermatology ranges from a variety of psychophysiologic disorders, where psychological stress plays a major role in precipitating and exacerbating skin disease, to primary or secondary psychiatric disorders, where the skin lesions are self-induced in the context of having no real skin disease or of having emotional problems secondary to existing skin disease [4]. Additionally, cutaneous side effects of psychotropic medications and psychiatric manifestations of some drugs used in dermatological practice also come under the domain of psychodermatology [5].

Common psychopathologies underlying psychodermatologic disorders are anxiety, depression, delusion and obsession-compulsion [6].

Trichotillomania is defined as hair loss from a patient's repetitive self-pulling of hair. The hair is then often ingested (trichophagia), with the associated risk of formation of a hair ball (trichobezoar) in the gastrointestinal tract, potentially interfering with peristalsis and causing related complications [7].

In dermatitis artefacta, the patient creates skin lesions to satisfy an internal psychological need, usually a need to be taken care of. The clinical presentation is characteristic, and differs from that of neurotic excoriations, delusional disorders, malingering, and Munchausen's syndrome. The condition tends to wax and wane with the circumstances of the patient's life [8].

Intradermal kerosene injection causing fasciitis and necrosis, is self mutilation practice that has been reported among adults. It is self mutilation practice that has been reported among adults; however only four cases were documented and all of them were in Arab communities. In Iraq it is not uncommon problem among children to have accidental oral ingestion or inhalation of kerosene while in adult oral intake or bathing with kerosene were used as a suicidal attempt [9] [10].

Delusions of parasitosis are a psychiatric disorder in which the patients have a fixed, false belief of being infested with parasites. Patients with delusions of parasitosis usually reject psychiatric referral. Even though it is a psychiatric disorder, these patients usually present to a dermatologist because they are convinced they have a dermatologic problem [11].

Psychogenic excoriation is a disabling disorder characterized by a repetitive picking of the skin. Psychogenic excoriation is characterized by symmetric, linear excoriations on accessible parts of the body (face, chest wall, extensor aspects of extremities, and upper back) with notable sparing of the upper lateral areas of the back. Skin lesions such as acne, scars, calluses, and insect bites are sometimes the sites for excoriations [12] [13].

So the aim of the present work was to assess the frequency of the major disorders of so-called psychocutaneous disorders that are commonly seen among Iraqi population.

\section{Patients and Methods}

This case descriptive study had been carried out in Department of Dermatology-Baghdad Teaching Hospital, Medical City, Baghdad, Iraq during the period from March 2012 to October 2013. As the objective of present work is to collect the main diseases in the group of the specific psychocutaneous disorders including: trichotellomenia, dermatitis artefecta and delusion of parasitosis.

All these cases were collected and categorized according to the disease problem. Cases were interviewed to search for the main triggering and precipitating factors involved in pathogenesis of these disorders, the clinical 
picture where well described in order to reach a final diagnosis. Psychological interview and analysis was carried out for many patients to reach the specific emotional and psychiatric disease by consultant psychiatrist.

A total of 100 patients with major psychocutaneous disorders where seen and evaluated, 19 were males and 81 were females. Their ages ranged from 7 - 73 years with a mean \pm SD of $26.5 \pm 14.722$ years.

Formal consent was taken from each patient or their parents after full explanation about the goal and nature of the present work. Also, ethical approval was taken from the scientific council of Dermatology and Venereology-Arabic Board for Medical Specializations. History and dermatological examination were performed to each patient regarding all soicodemographic points related to the disease

Digital photographs were taken using SONY Cyber-Shot T300 10.1 MP for each patient in good illumination.

\section{Results}

A total of 100 patients with major psychocutaneous disorders were seen and evaluated. Nineteen were males and 81 were females with female to male ratio: 4.26:1. Their ages ranged from $7-73$ years with a mean \pm SD of $26.5 \pm 5.217$ years.

The frequency of these diseases was as follow: trichotillomania $53 \%$, dermatitis artifacta $37 \%$, delusion of parasitosis $6 \%$ and neurotic excoriation $4 \%$.

Trichotillomania: It was the major problem among these patients, their ages ranged from 7 - 65 years with a mean \pm SD of $23.5 \pm 12.73$ years, females were 45 (84.9\%) patients and were the major sex affected and males were 8 (15.1\%) patients, so trichotillomania is a disease of young female patients.

Family history was negative in all patients, and all patients denied their action except 3 (5.7\%) admit their action. Remission that lasted for few months was seen in 47 (88.7\%) patients and then relapsed again.

Psychological assessment was done for 49 (92.5\%) patients and all had obsessive compulsive neurosis features.

Regarding the sites, 50 (93.9\%) patients showed scalp involvement while only 3 (6.1\%) patients had involvement of eyebrows and eyelashes.

Single patches were seen in 33 (62.7\%) patient, while multiple patches ranged from 2 - 5 in 20 (37.3\%) patients.

Patients often presented with areas of different hair lengths, some with a broken hairs and some with tapered ends as new normal growth. Some hairs may be broken mid-shaft or appeared as uneven stubble, whereas others had small black dots at the surface of the scalp, these features simulating fire in field. Overall hair density is normal. There is usually no scaling on the scalp. A pull test was negative, i.e., the hair does not pull out easily. The affected area often had an unusual strange shape, which had a useful diagnostic clue.

The hair loss in trichotillomania might take many shapes, morphological forms or patterns as we found that crest like in (23.2\%), where there was loss of hair at the sides of the scalp leaving the frontovertical and occipital area were not affected (Figure 1).

The second pattern so called cap like (20.8\%), where there was a hair loss at the top of the scalp mainly fronto-vertical area and leaving the sides of the scalp (Figure 2).

The third pattern alopecia areata like (35.2\%), where multiple patches of hair loss were seen (Figure 3).

The forth pattern frontal baldness like (20.8\%), where the patients presented with complete hair loss of the frontal hair only (Figure 4).

Dermatitis artifacta (factitial dermatitis): It was the second major psychocutaneous disorder that was seen in $37 \%$ of patients, females were the major sex affected, 30 (80.1\%) patients, while males were affected only 7 (18.9\%) patients, their ages ranged from 10 - 73 years with a mean \pm SD of $27.1 \pm 15.34$ years.

Family history was negative in all patients, and all patients denied their action except 6 (15.4\%) of them admitted about their disease.

Psychological assessment was done for 33 (84.6\%) patients and all of them had impulsive personality disorder.

All patients present with multiple lesions and all lesions were within the reach of the hands.

The technique of producing the disease was as follow: burning (15.4\%), sharp instruments (53.9\%) or injection of chemical material like kerosene (28.2\%), and painting the skin (2.5\%).

Regarding the sites: 34 (87.2\%) patients involved upper and lower extremities and 5 (12.8\%) patients had face involvement.

The margins were sharp, clearly demarcated from adjacent normal skin, and borders were angulated and 


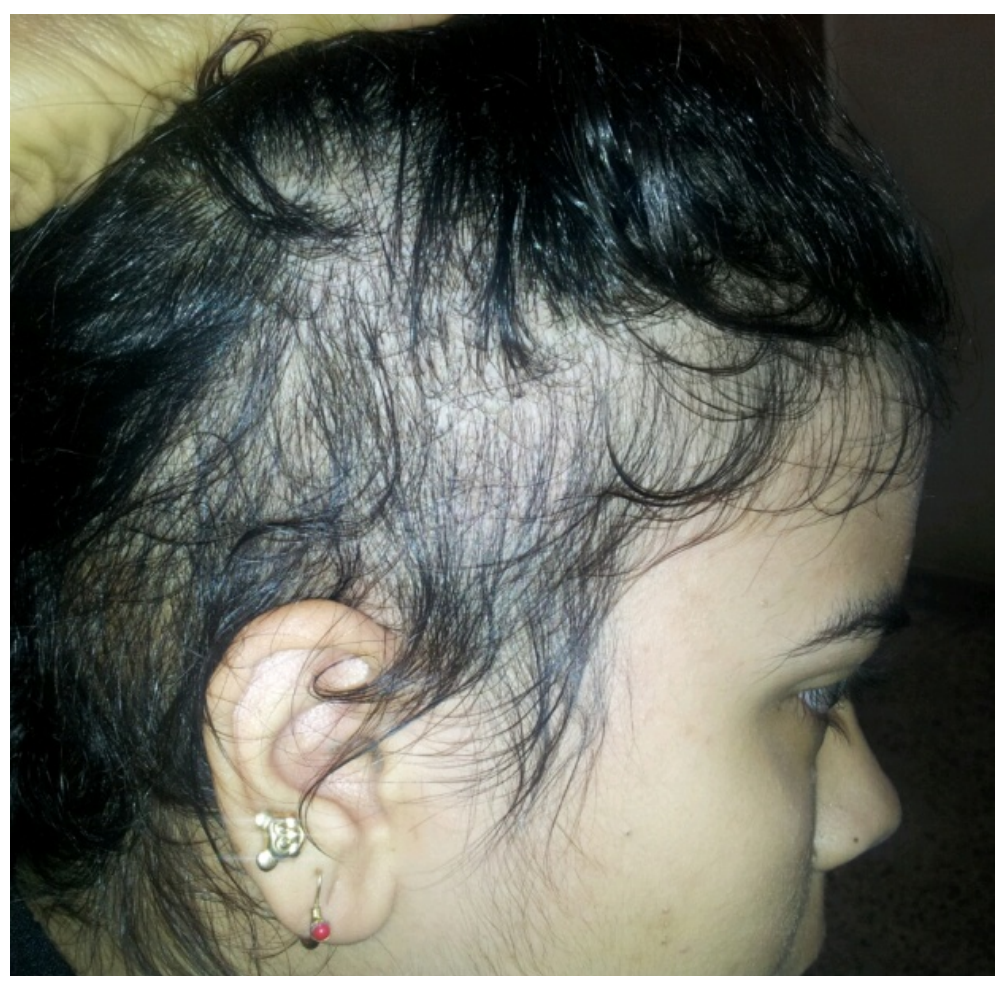

Figure 1. Twenty five years old female with hair loss at the sides of the scalp resembling the crest.

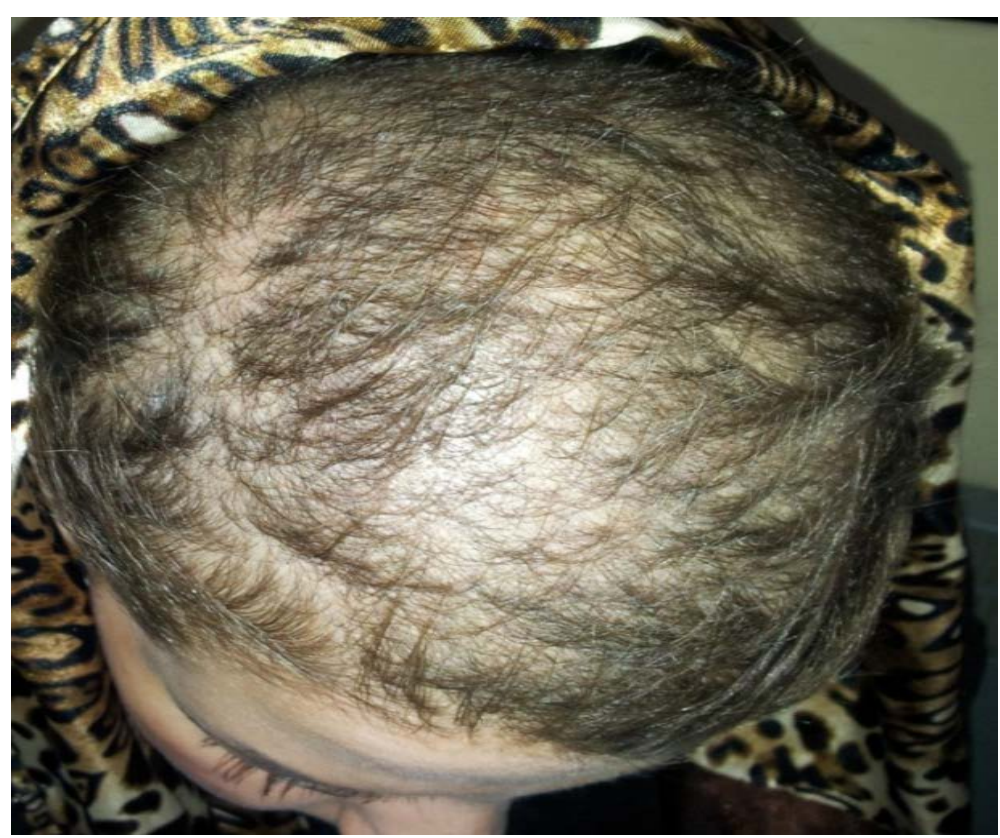

Figure 2. Nineteen years old female with frontovertical hair loss resembling cap like.

geometric, while the surface was crusted and necrotic, abraded or atrophic, which indicate the strange pathways exploited by the creator's hand according to his strange psychological abnormalities.

The lesions appeared fully formed, all at the same stage of development and all patients was unable to elicit evidence of evolutionary changes (Figure 5 \& Figure 6). 


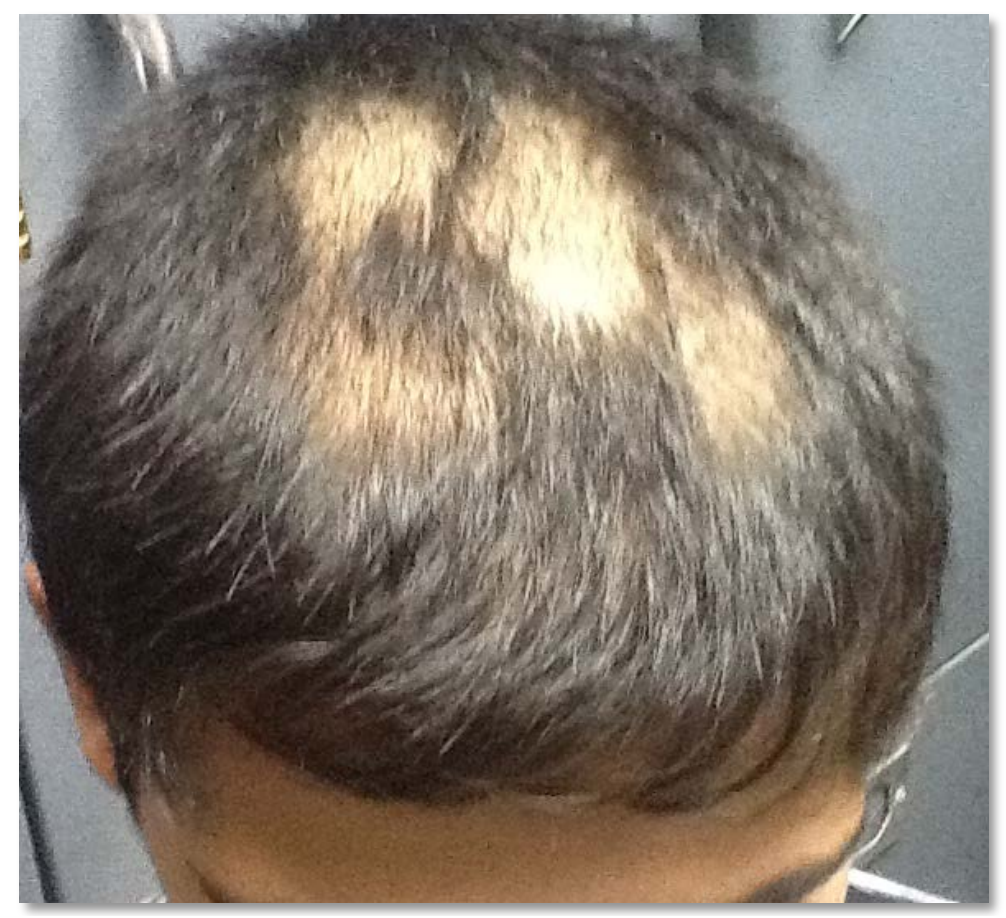

Figure 3. Thirteen years male with multiple patches of hair loss so-called alopecia areata like.

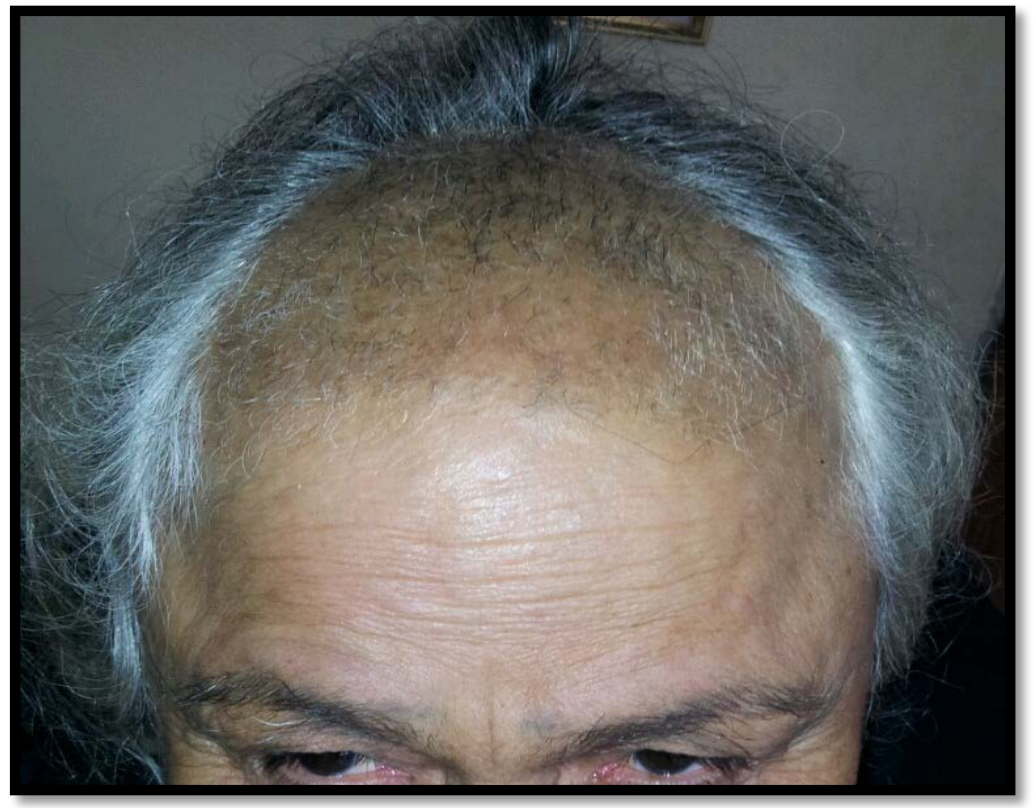

Figure 4. Sixty five years female with frontal hair loss.

Delusion of parasitosis: It was the third disorder was seen in $6 \%$ of patients, females were 4 (60.0\%) patients, while males were $2(40.0 \%)$ patients, their ages ranged from 20 - 60 years with a mean \pm SD of $40.4 \pm 18.52$ years.

Psychological assessment was done for all patients. All patients had mono-symptomatic delusional state, they are completely aware about surrounding and insight with no other features of schizophrenia or other psychotic conditions. 


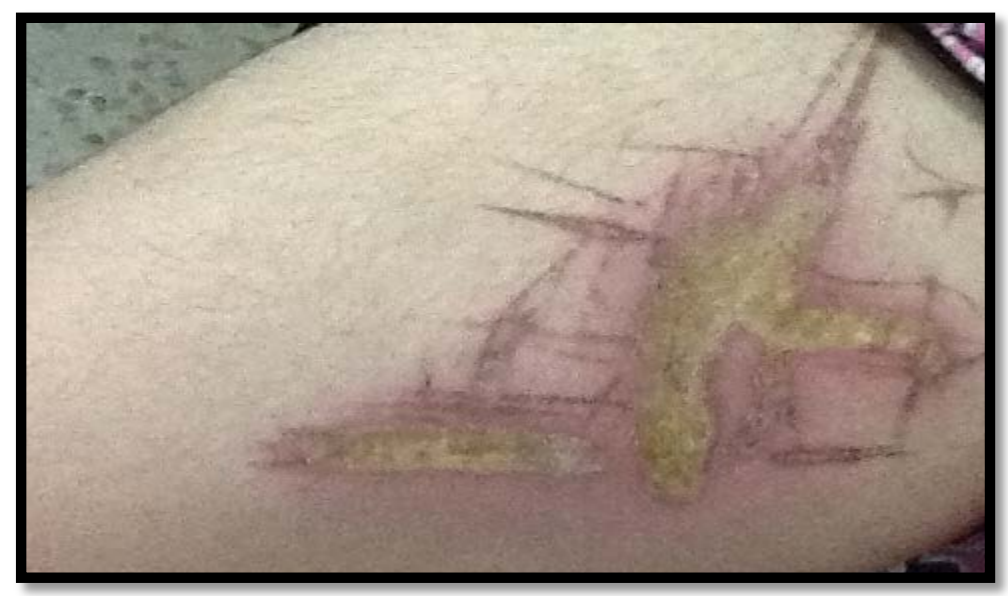

Figure 5. Twenty five years female showing involvement of inner aspect of right thigh induced by sharp instrument.

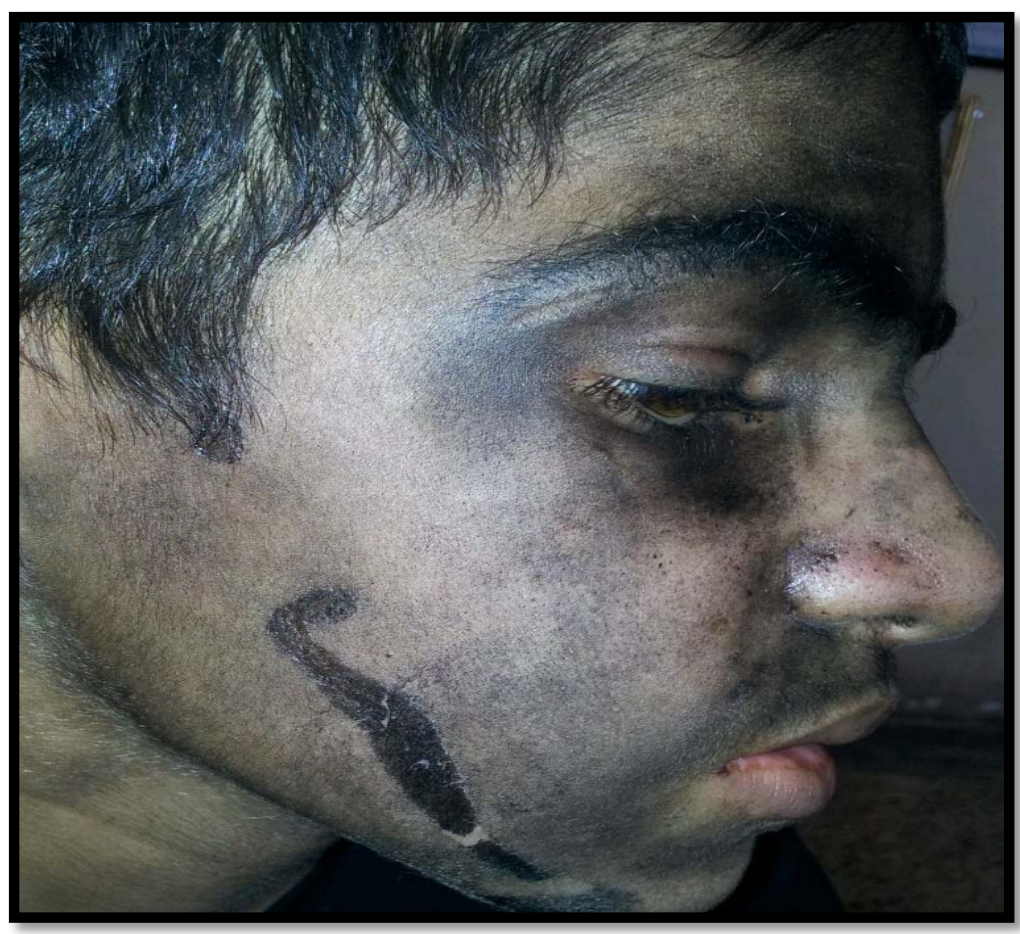

Figure 6. Fifteen years old male painting his face with black dye.

Patients described cutaneous symptoms of crawling, biting, and stinging sensations as the first evidence of infestation. Some patients described an elaborate "life cycle" of these parasites with vivid descriptions of how they "breed and multiply" or "bury themselves and die" in the skin. They usually had tried various strategies for eradicating the alleged parasites, such as using pesticides on themselves and their possessions.

Patients were frequently bring in bits of skin, lint, tissue paper, and other samples of "parasites" to try to prove the existence of these alleged parasites (Figure 7).

Cutaneous findings ranged from none at all to excoriations, lichenification, prurigo nodularis and frank ulcerations. All of which are factitious in origin resulting from the patient's efforts to dig out the parasites.

Neurotic excoriations (skin-picking syndrome): It was the least disease seen in this study (4\%), four patients were seen, three of them were females (80\%) and one male (20\%), their ages ranged from 23 - 55 years, with a mean \pm SD of $39.6 \pm 14.69$ years. 


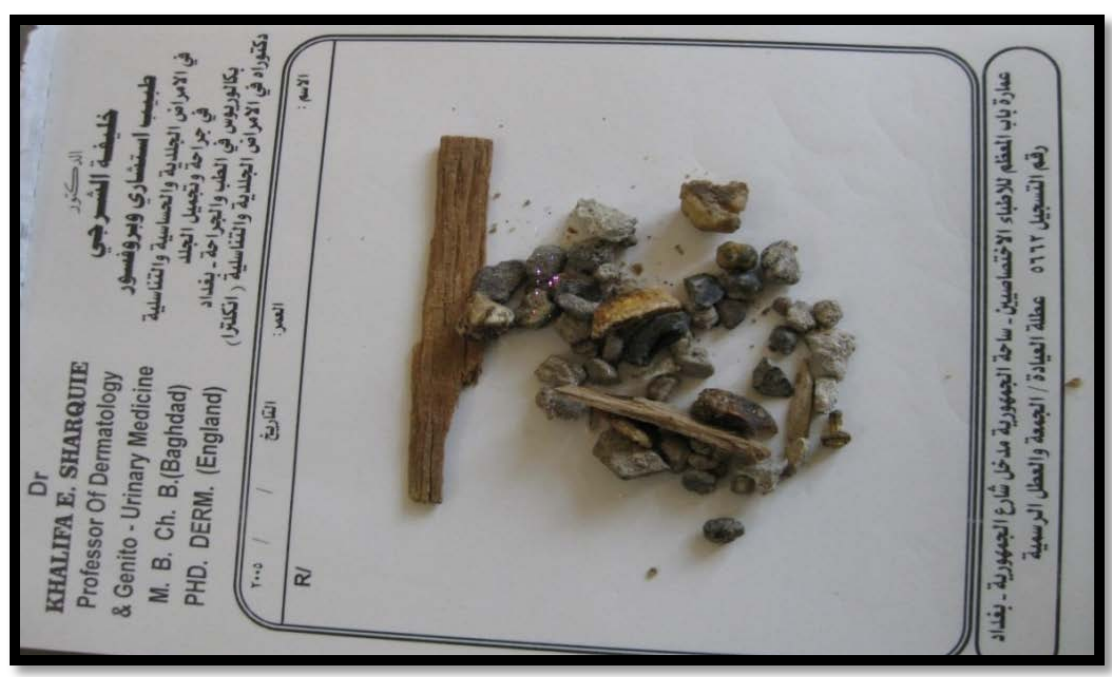

Figure 7. Sixty eight years old male says that he collect these materials from his skin.

Psychological assessment was done for all patients and all of them had history of anxiety and depression. The patients presented with symmetric, linear excoriations confined to areas within reach of the hands like face, chest wall, and extensor aspects of extremities, and upper back with notable sparing of the upper lateral areas of the back, the excoriation occurred as a response to mainly itchy and sometimes burning of the skin. Active lesions were round or linear, clean or crusted, scooped-out ulcers. The margins of the older lesions were thickened from repeated picking.

Lesions varied in number from one to dozens. Skin lesions such as acne, scars, and insect bites were the sites for excoriations. The repeated excoriations led to an itch-scratch cycle that perpetuates the condition. Post-inflammatory hypo- or hyperpigmentation and scarring were seen. Picking was most often accomplished by the fingernails. But it might also be carried out with needles, tweezers, or whatever instrument may come to hand (Figure 8).

\section{Discussion}

Emotional problems are so common, that is an event in the life of all people, and these psychological problems could be minor one that pass unnoticed or a major one that cause health problems. On contrary some patients with severe skin disorders might disturb the normal psychological course of a healthy individual, and might exacerbate the primary disease itself or present with new manifestation unrelated to the primary problem, like non itchy acne vulgaris present with itching, or non itching psoriasis might present with itching or koebner's phenomenon, or some patient with minor or severe skin problem might present with features of neurosis or depression [5] [14].

The present study had evaluated the major psychocutaneous diseases that are commonly encountered in daily clinical practice:

Trichotillomania was the major problem of young female patients with a mean age 23.5 year and this was not comparable with other studies where they found the mean age is around 13 years [15]. Family history was negative in all patients and this is similar to what has been published [16]. The clinical picture of trichotillomania was not well elucidated in all previous reports but the present study for the first time had described well morphological patterns which might help in establishing the right diagnosis. These patterns where mainly alopecia areata like patchy type, frontal baldness like cap-like and crest like.

The hair loss in trichotillomania had well established features that also assist in reaching the diagnosis, as the hair loss is not uniform but rather in a crazy form, in some areas complete hair loss while the adjacent area had long stumps of broken hair and on other area there is growing hair, this is so-called fire in field. These diagnostic features of the disease are well not discussed in the medical literatures.

Trichotillomania especially in the bizarre type could be easily misdiagnosed with alopecia areata as in both we can have patchy hair loss, but there are certain different points that can distinguish between these two condi- 


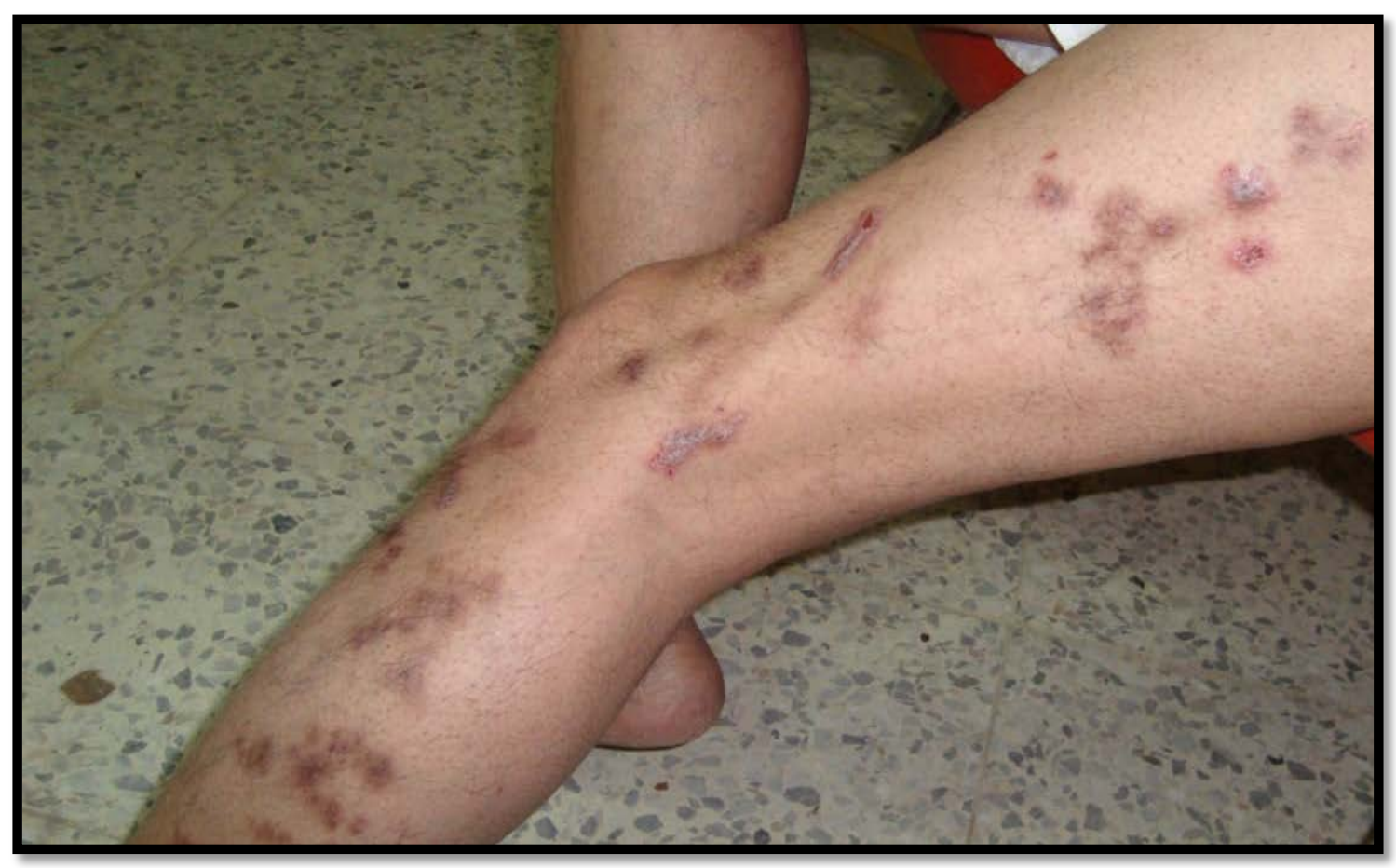

Figure 8. Fifty five years male showed prurigo nodular like lesions of extensor aspect of right lower extremity.

tions, like the fire in field feature is not well recognized in alopecia areata. In alopecia are at a usually there is a complete hair loss or there is early complete hair growth and there is nothing between, and exclamation mark hair are good helpful diagnostic sign in favor alopecia areata especially in the early active form. The only type of alopecia areata that could not be easily separated from trichotillomania is the moth eaten alopecia which is not un common variety of alopecia areata [16], in addition the presence of nail changes are more in favor of alopecia areata, and lastly patient with trichotillomania almost always had obsessive compulsive neurosis.

Dermatitis artifacta was the second most common disorder in the present study where the majority of patients were females with a mean age of 27.1 year and this is comparable to what has been published.

This problem was much more common in this study when compared with other studies abroad like European countries [8], otherwise the clinical picture is not much different to what had been reported in the medical literatures.

Delusions of parasitosis was the third common problem reported in the present work but it is the major problem published elsewhere, as it is the most common in European countries [17].

The mean age seen in the present study was 41.4 year while it ranges from 55.6 - 56 year in another studies. All patients had monosymptomatic hypochondriacal psychosis, otherwise their personality is well preserved [18]. The clinical picture seen in the present work was not much different from what had been published [19].

Psychogenic or neurotic excoriation which characterized by excessive scratching of skin with minimal lesions like acne or apparently normal skin, the mean age 40.4 year which is very much comparable with other studies [12] [20].

\section{Conclusions}

The major psychocutaneous diseases in Iraqi population were trichotillomania, dermatitis artifacta, delusion of parasitosis and neurotic excoriations. Trichotillomania is the major problem in the present work, while delusion of parasitosis is the main problem in other countries like European countries and all of them are mostly diseases of females, affecting very young people like in trichotillomania and dermatitis artifacta while other diseases like neurotic excoriation and delusion of parasitosis are diseases of middle age.

Trichotillomania had very characteristic diagnostic patterns which are not discussed in previous studies. 


\section{Disclosure}

This study was an independent study and not funded by any companies or associations.

\section{References}

[1] Koo, J.Y.M., Do, J.H. and Lee, C.S. (2000) Psychodermatology. Journal of American Academy of Dermatology, 43, 848-853. http://dx.doi.org/10.1067/mjd.2000.109274

[2] Augustin, M., Gieler, U. and Zschocke, I. (2004) Psychodermatology Has Come out of Its Infancy. Dermatol Psychosom, 5, 3-4. http://dx.doi.org/10.1159/000078047

[3] Gieler, U. (2007) Psychodermatology. European Journal of Dermatology, 17, 106-107.

[4] Jafferany, M. (2007) Psychodermatology: A Guide to Understanding Common Psychocutaneous Disorders. The Primary Care Companion-Journal of Clinical Psychiatry, 9, 203-213. http://dx.doi.org/10.4088/PCC.v09n0306

[5] Koo, J.Y. and Lee, C.S. (2003) General Approach to Evaluating Psychodermatological Disorders. In: Koo, J.Y. and Lee, C.S., Eds., Psychocutaneous Medicine, Marcell Dekker, Inc, New York, 1-29.

[6] Poot, F., Sampogna, F. and Onnis, L. (2007) Basic Knowledge in Psychodermatology. Journal of the European Academy of Dermatology and Venereology, 21, 227-234. http://dx.doi.org/10.1111/j.1468-3083.2006.01910.x

[7] American Psychiatric Association (2000) Diagnostics and Statistics Manual of Mental Disorders. 4th Edition, Text Revision, American Psychiatric Association, Washington, 122-126.

[8] Cotterill, J.A. (1992) Self-Stigmatization: Artefact Dermatitis. British Journal of Hospital Medicine, 47, 115-119.

[9] Terzi, C., Bacakoglu, A., Unek, T. and Ozkan, M.H. (2002) Chemical Necrotizing Fasciitis Due to Household Insecticide Injection: Is Immediate Surgical Debridement Necessary? Human \& Experimental Toxicology, 21, 687-690. http://dx.doi.org/10.1191/0960327102ht308cr

[10] Sharquie, K.E., Noaimi, A.A., Solaiman, M.Y. and Sami, B. (2014) Kerosene Induced Panniculitis in Iraqi Patients. Journal of Cosmetics, Dermatological Sciences and Applications, 4, 323-328. http://dx.doi.org/10.4236/jcdsa.2014.45042

[11] Wykoff, R.E. (1987) Delusions of Parasitosis: A Review. Clinical Infectious Diseases, 9, 433-437. http://dx.doi.org/10.1093/clinids/9.3.433

[12] Arnold, L.M., Auchenbach, M.B. and McElroy, S.L. (2001) Psychogenic Excoriation: Clinical Features, Proposed Diagnostic Criteria, Epidemiology and Approaches to Treatment. CNS Drugs, 15, 351-359. http://dx.doi.org/10.2165/00023210-200115050-00002

[13] Grant, J.E. and Odlaug, B.L. (2009) Updates on Pathological Skin Picking. Current Psychiatry Reports, 11, $283-288$. http://dx.doi.org/10.1007/s11920-009-0041-x

[14] Gupta, M.A. and Gupta, A.K. (1996) Psychodermatology: An Update. Journal of the American Academy of Dermatology, 34, 1030-1046. http://dx.doi.org/10.1016/S0190-9622(96)90284-4

[15] Tay, Y.K., Levy, M.L. and Metry, D.W. (2004) Trichotillomania in Childhood: Case Series and Review. Pediatrics, 113, 494-498. http://dx.doi.org/10.1542/peds.113.5.e494

[16] Sharquie, K.E., Noaimi, A.A. and Hameed, A.F. (2013) Lichen Planopilaris Is a Common Alopecia among Iraqi Population. Journal of Cosmetics, Dermatological Sciences and Applications, 5, 35-39. http://dx.doi.org/10.4236/jcdsa.2013.33A1005

[17] Freudenmann, R.W., Lepping, P. and Huber, M. (2012) Delusional Infestation and the Specimen Sign: A European Multicentre Study in 148 Consecutive Cases. British Journal of Dermatology, 167, 247-251.

[18] Trabert, W. (1999) Shared Psychotic Disorder in Delusional Parasitosis. Psychopathology, 32, 30-34. http://dx.doi.org/10.1159/000029063

[19] May, W.W. and Terpenning, M.S. (1991) Delusional Parasitosis in Geriatric Patients. Psychosomatics, 32, 88-94. http://dx.doi.org/10.1016/S0033-3182(91)72116-6

[20] Freunsgaard, K. (1984) Neurotic Excoriations. A Controlled Psychiatric Examination. Acta Psychiatrica Scandinavica, 312, 1-52. 